\title{
32. PALEOMAGNETISM OF IGNEOUS AND SEDIMENTARY SAMPLES ${ }^{1}$
}

William Lowrie and Neil D. Opdyke, Lamont-Doherty Geological Observatory, Palisades, New York

\section{INTRODUCTION}

At Sites 146, 150, 151, 152 and 153 of Leg 15, drilling terminated after penetrating diabase sills, which on the basis of fossils in the overlying sediments are thought to be possibly Upper Cretaceous in age. Preliminary paleomagnetic measurements have been carried out on twenty-three igneous specimens from these sites and on eleven specimens from the adjacent sediments at Sites 146 and 152 .

The igneous specimens were of sufficient size to allow cylindrical samples one inch in diameter and one inch in height to be prepared by drilling with a diamond-tipped bit in the downward vertical direction. This was the only known sample orientation. Fiducial azimuthal markings were inscribed which proved useful in considering changes in magnetization of the samples.

At Sites 146 and 152, samples were obtained from limestones overlying and underlying the diabase. Again, the samples were in the form of one-inch cylinders inscribed with the downward vertical direction. In addition, a common fiducial mark was inscribed on all samples from the same limestone section.

The remanent magnetizations of the samples were measured with a $105 \mathrm{~Hz}$ spinner magnetometer using a six-spin technique. Susceptibilities of the samples were measured with an AC bridge. Sample volumes were measured using an air pycnometer. Alternating-field (AF) demagnetization was carried out by tumbling each sample at different rates simultaneously about two orthogonal axes inside a demagnetizing coil. The amplitude of the alternating current in this coil was modulated smoothly by a large motor-driven variable inductance in series. Two mutually orthogonal pairs of Helmholtz coils were used for cancellation of the ambient field.

Complete progressive $\mathrm{AF}$ demagnetization curves were obtained for each sample. The intensity variations for representative igneous specimens from Site 146 are shown in Figures 1 and 2. Curves for all the igneous specimens from Sites 150, 151, 152 and 153 are shown in Figures 3, 4, 5 and 6 respectively. Curves for the limestone specimens from Site 146 are shown in Figures 7 and 8, and from Site 152 in Figure 9.

\section{IGNEOUS SAMPLES}

In general, the igneous samples were easily demagnetized. The directions of magnetization were stable during measurement and soft components were usually removed by fields less than 75 oe. For each specimen the individual stable direction was close to the remanent direction after

\footnotetext{
${ }^{1}$ Lamont-Doherty Geological Observatory Contribution No. 1731 .
}

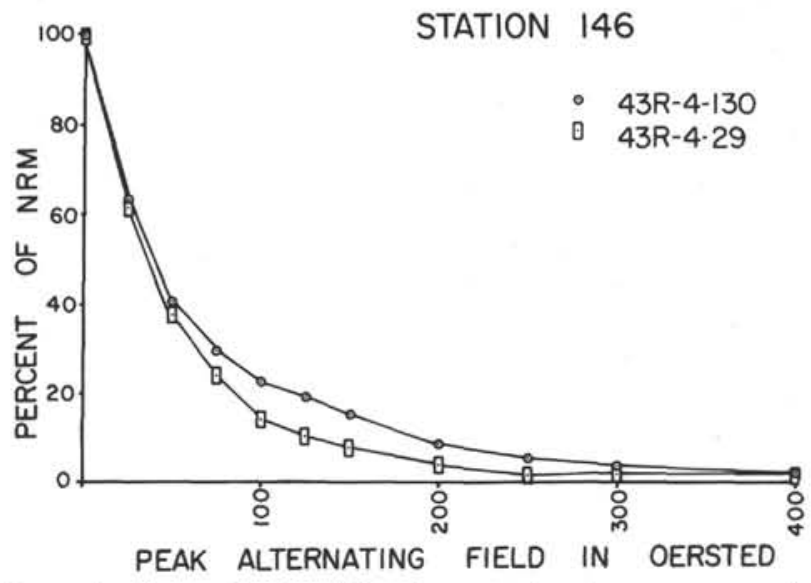

Figure 1. Normalized $A F$ demagnetization curves for igneous samples - Site 146.

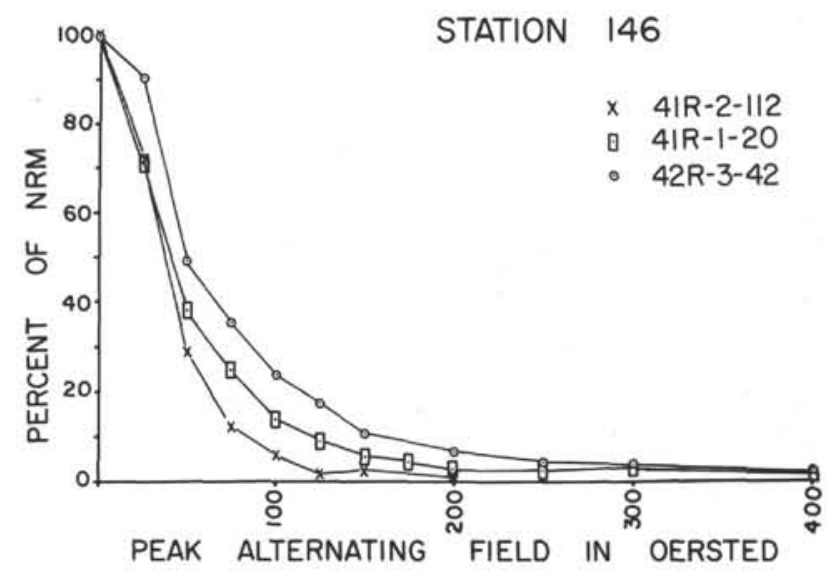

Figure 2. Normalized $A F$ demagnetization curves for igneous samples - Site 146.

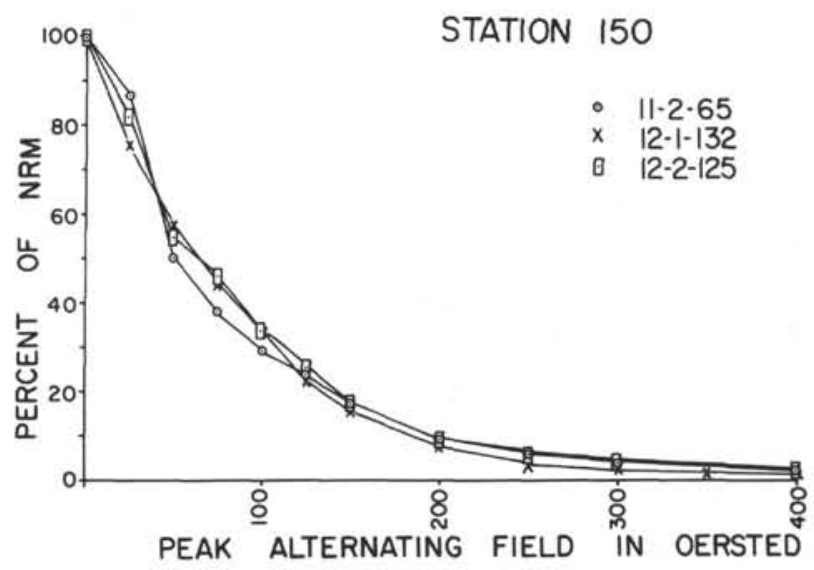

Figure 3. Normalized AF demagnetization curves for igneous samples - Site 150. 


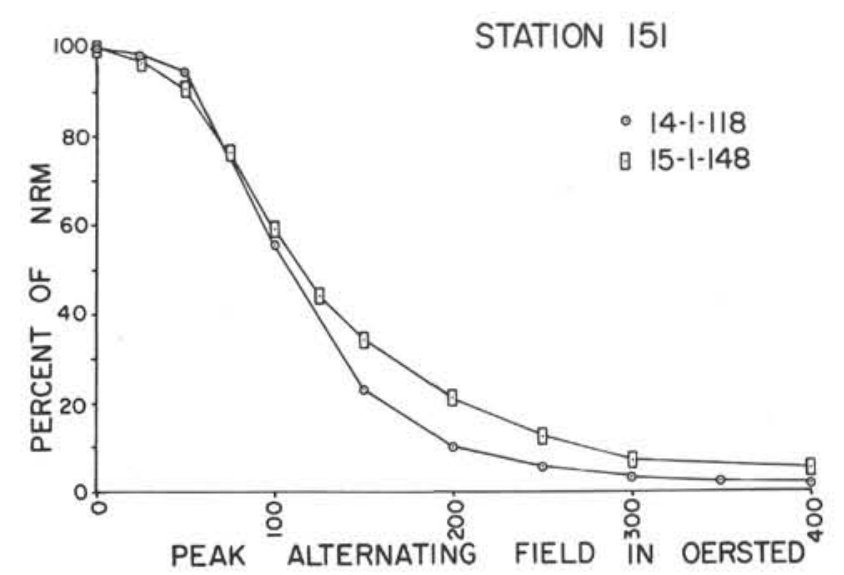

Figure 4. Normalized AF demagnetization curves for igneous samples - Site 151.

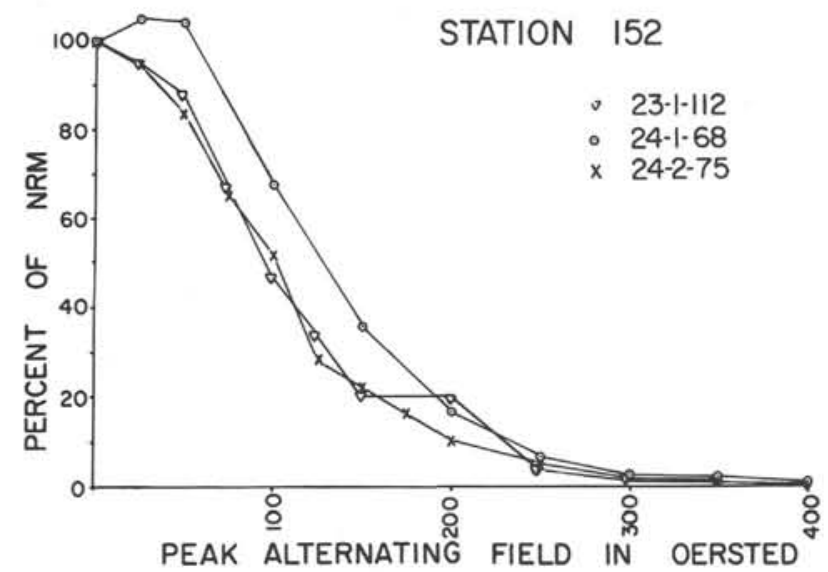

Figure 5. Normalized $A F$ demagnetization curves for igneous samples - Site 152.

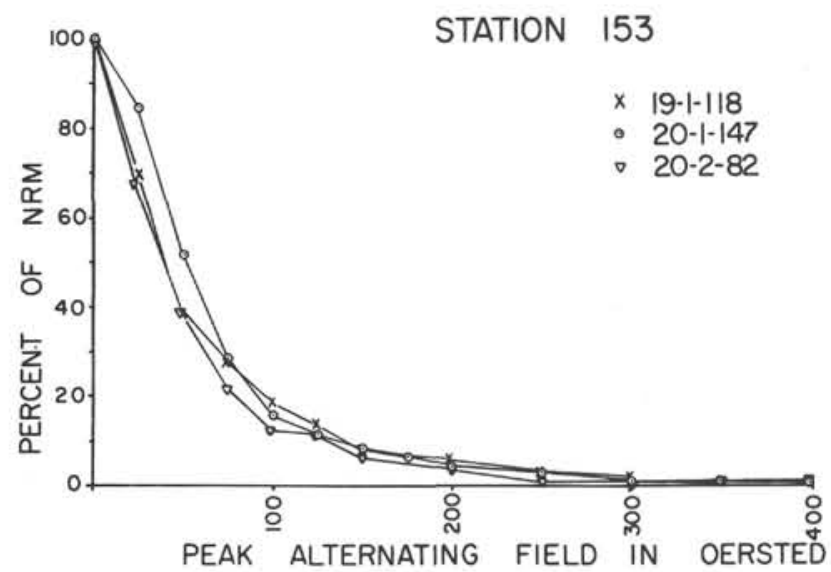

Figure 6. Normalized AF demagnetization curves for igeneous samples - Site 153.

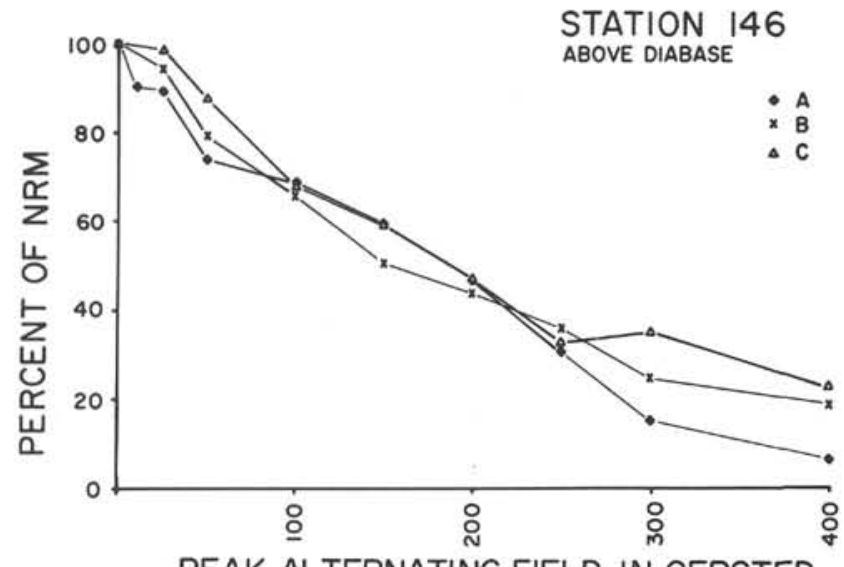

PEAK ALTERNATING FIELD IN OERSTED

Figure 7. Normalized AF demagnetization curves for limestone samples - Site 146.

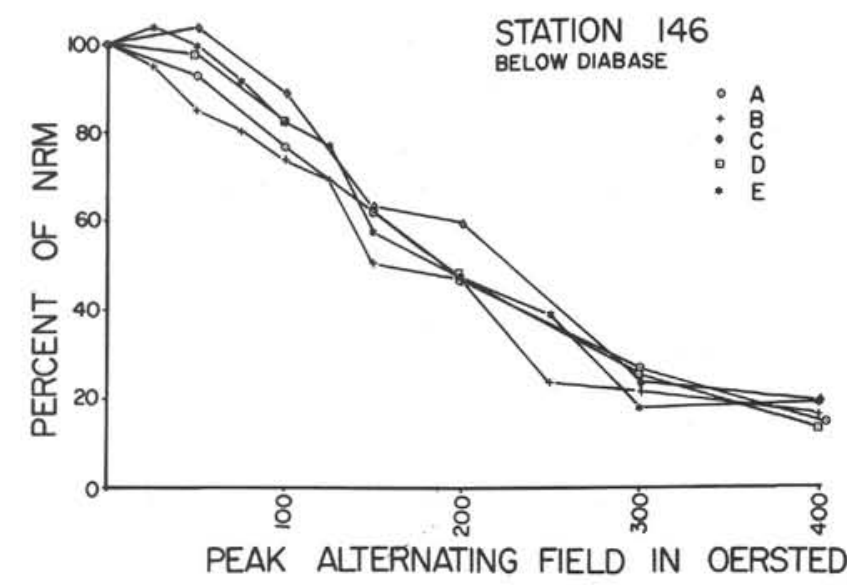

Figure 8. Normalized AF demagnetization curves for limestone samples - Site 146.

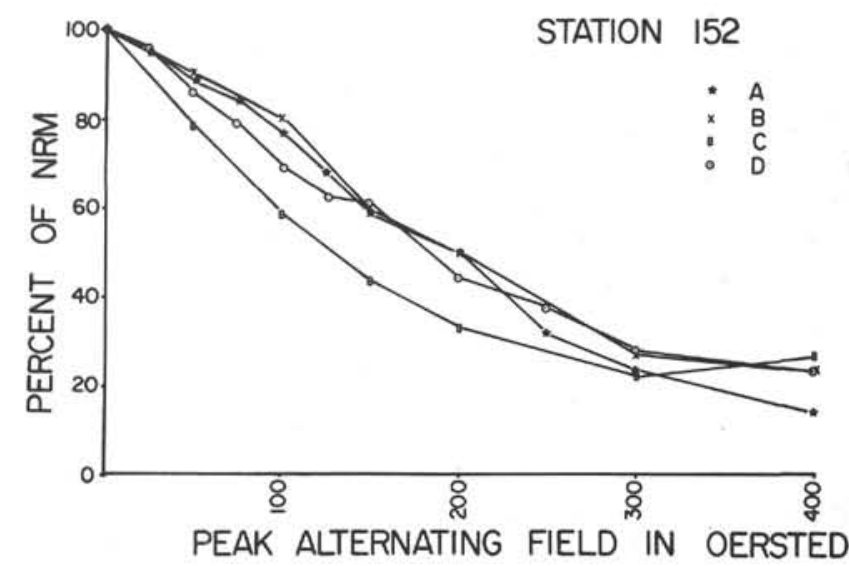

Figure 9. Normalized $A F$ demagnetization curves for limestone samples - Site 152. 
AF treatment in a 100 oe field. The directions of the natural remanent magnetism (NRM) and remanence after 100 oe cleaning are listed in Table 1 . The intensity of NRM $\left(\mathrm{J}_{\mathrm{r}}\right)$, the weak field susceptibility $(\mathrm{k})$, and the ratio

$$
Q n^{\prime}=J_{r} / k
$$

are also listed in Table 1.

The directions remained reasonably stable in most cases until the intensity fell below about 5 to 10 percent of the NRM. The magnetizations then showed an instability characterized by apparent growth or decay of the remanence in less than a minute during the first of the six spins. After magnetic cleaning in higher alternating fields, this instability was found to extend into all six spins making further measurements meaningless. Progressive $\mathrm{AF}$ demagnetization was discontinued at this point. No indications of anhysteretic remanence effects were discernible.

The origin of the instability in specimen 41R-2-2 was investigated with a simple test. After demagnetizing in 200 oe, the intensity was $3.5 \times 10^{-5}$ Gauss. The specimen was left for 30 minutes in the horizontal component of the earth's field $(0.22 \mathrm{oe})$ and then measured. It was found to have acquired an additional component of magnetization of intensity $4.0 \times 10^{-5}$ Gauss in the direction of the applied field. The intensity of this viscous remanence (VRM) decayed very noticeably while it was being measured. The origin of the instability thus appeared to be the relaxation of a short-time-constant VRM picked up between the demagnetization apparatus and the spinner magnetometer.

Measurements of isothermal remanent magnetization (IRM) produced in different fields indicated that saturation IRM could probably be produced in fields of 500 to 600 oe. However, a 4-inch electromagnet was used to produce saturation IRM in 9000 oe. This remanence was progressively destroyed by producing IRM's in the opposite direction with a large coil. The field required to achieve zero net remanence (the remanent coercivity) was found for each sample (Table 1). Although remanent coercivity does not directly reflect the hardest coercivities of a remanence, it is an indication of the hardness of the magnetically less stable half of the total spectrum of coercivities in a specimen since in measuring the parameter this soft fraction is effectively balanced against the harder fraction. The remanent coercivities of the present samples were low, ranging from 55 to 143 oe. This indicates that the total spectrum of coercivities of each rock contains an appreciable soft component.

The coercivity fraction carrying the NRM may be quantitatively estimated by measuring the alternating field required to randomize half of the coercivities carrying the NRM. These median destructive fields (m.d.f.), read directly from the progressive $\mathrm{AF}$ demagnetization curves (Fahrig et al., 1971), are also listed in Table 1. From their low values relative to the remanent coercivities it is evident that the bulk of the NRM intensity is carried by the soft fraction of coercivities in each sample.
The $\mathrm{Q}_{\mathrm{n}}{ }^{\prime}$ ratios are high enough to suggest that the in situ magnetizations are dominated by the remanence. However, in view of the relatively large amount of low coercivity magnetic components present in these samples and their tendency to acquire VRM easily it is possible that original in situ magnetizations may be obscured by the soft fraction.

The inclinations of the stable directions of NRM were averaged at each site. The site locations, present field inclinations, axial dipole field inclinations, and the specimen average inclinations are shown in Table 2. Invariably, as shown in both Table 1 and Table 2, the inclinations of the stable remanences, whether normal or reversed, were considerably shallower than either the present field inclinations or the axial dipole field inclinations at these stations.

The Cretaceous pole positions found from the North American, Caribbean, and South American rocks by several authors were used to calculate the Cretaceous field inclinations at the sampling stations. The results are listed in Table 3. The average inclinations of the stable directions found in the present study range from about 3 to 17 degrees. These inclinations from the central Caribbean Sea are compatible with the data from Jamaica, Puerto Rico, Colombia, and Venezuela (0-20 degrees, approx.). The inclinations are clearly different from the inclinations calculated from Cretaceous poles derived from Brazil, Peru, and Argentina (30-40 degrees, approx.). Cretaceous inclinations derived from North American rocks are slightly different from the Caribbean Sea data, but the difference may not be significant.

\section{SEDIMENTARY SAMPLES}

The declinations and inclinations of the limestones are listed in Table 4, together with their magnetization intensities, susceptibilities, $\mathrm{Q}_{\mathrm{n}}{ }^{\prime}$-ratios, remanent coercivities, and median destructive fields. The limestone magnetizations were much more stable than those of the diabase samples. This is evident in Figures 7,8, and 9 and in the relatively high remanent coercivities and median destructive fields depicted in Table 4.

All of the limestones were normally magnetized. At Site 146 the stable directions of the limestones above and below the diabase (Table 4) were similar to the directions measured for the diabase itself (Table 1). The NRM intensities, susceptibilities, $\mathrm{Q}_{\mathrm{n}}{ }^{\prime}$-ratios, and median destructive fields of the metamorphosed limestones did not differ remarkably from those of the unaltered specimens. This might suggest that the heating which produced discoloration of the altered limestone may not have been at a sufficiently high temperature to substantially alter the magnetic minerals or to give them a thermo-remanent magnetization. The only difference between the two limestones is in their remanent coercivities which are lower in the altered group. This may be an original depositional effect, and not one which reflects different thermal histories of the two sets of specimens. 
TABLE 1

Summary of Results for Diabase Specimens

\begin{tabular}{|c|c|c|c|c|c|c|c|c|c|c|c|}
\hline \multirow{3}{*}{ 今ั } & \multirow{3}{*}{ } & \multirow{3}{*}{ 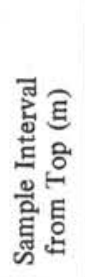 } & \multicolumn{4}{|c|}{ Direction } & \multirow{3}{*}{ 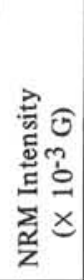 } & \multirow{3}{*}{ 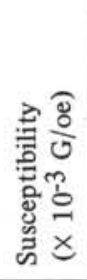 } & \multirow[b]{3}{*}{ 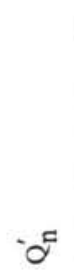 } & \multirow{3}{*}{ 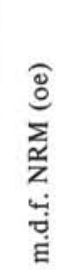 } & \multirow{3}{*}{ 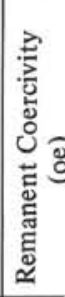 } \\
\hline & & & \multicolumn{2}{|c|}{ NRM } & \multicolumn{2}{|c|}{$100 \mathrm{oe}$} & & & & & \\
\hline & & & D & I & D & I & & & & & \\
\hline \multicolumn{3}{|c|}{ Site 146} & & & & & & & & & \\
\hline 41 & 1 & 20 & 141.6 & 39.1 & 146.0 & 7.3 & 2.65 & 2.35 & 1.13 & 40 & 60 \\
\hline 41 & 1 & 118 & 290.2 & 26.7 & 277.3 & 12.7 & 4.20 & 2.23 & 1.89 & 33 & 60 \\
\hline 41 & 2 & 2 & 357.6 & 65.2 & 52.4 & 41.1 & 1.21 & 2.91 & 0.41 & 33 & 66 \\
\hline 41 & 2 & 112 & 266.1 & 71.0 & 242.3 & 31.8 & 1.49 & 3.23 & 0.46 & 38 & 78 \\
\hline 42 & 2 & 70 & 223.6 & 43.0 & 221.2 & 12.1 & 2.81 & 2.38 & 1.18 & 55 & 56 \\
\hline 42 & 3 & 42 & 137.8 & 22.0 & 145.3 & 8.9 & 4.37 & 2.22 & 1.97 & 49 & 69 \\
\hline 42 & 3 & 148 & 167.7 & 41.0 & 182.5 & 12.8 & 2.78 & 2.48 & 1.12 & 35 & 55 \\
\hline 43 & 2 & 22 & 200.2 & 84.0 & 267.3 & 15.0 & 5.22 & 1.19 & 0.61 & 31 & 64 \\
\hline 43 & 2 & 123 & 119.1 & 25.8 & 141.8 & 16.6 & 5.93 & 2.37 & 250 & 34 & 60 \\
\hline 43 & 3 & 73 & 92.7 & 26.3 & 110.0 & 6.7 & 3.79 & 2.53 & 1.50 & 44 & 57 \\
\hline 43 & 4 & 29 & 271.8 & 36.2 & 283.3 & 17.1 & 2.99 & 2.43 & 1.23 & 35 & 55 \\
\hline 43 & 4 & 130 & 97.1 & 34.8 & 82.9 & 21.5 & 4.98 & 2.47 & 2.02 & 37 & 57 \\
\hline \multicolumn{12}{|c|}{ Site 150} \\
\hline 11 & 2 & 65 & 276.5 & 36.4 & 269.0 & -15.3 & 3.92 & 1.83 & 2.14 & 50 & 71 \\
\hline 12 & 1 & 132 & 37.9 & 9.2 & 26.2 & -6.9 & 6.64 & 1.98 & 3.34 & 63 & 72 \\
\hline 12 & 2 & 125 & 50.7 & 16.3 & 33.9 & -0.8 & 4.69 & 2.06 & 2.14 & 63 & 70 \\
\hline \multicolumn{12}{|c|}{ Site 151} \\
\hline 14 & 1 & 118 & 46.4 & 34.3 & 48.5 & 25.8 & 5.84 & 1.59 & 3.66 & 110 & 131 \\
\hline 15 & 1 & 148 & 355.6 & 3.4 & 4.2 & -6.4 & 1.96 & 1.36 & 1.44 & 117 & 135 \\
\hline \multicolumn{12}{|c|}{ Site 152} \\
\hline 23 & 1 & 112 & 223.4 & 17.2 & 212.9 & -2.0 & 2.38 & 3.54 & 0.67 & 102 & 128 \\
\hline 24 & 1 & 67 & 108.4 & -7.1 & 104.4 & -17.9 & 1.68 & 3.33 & 0.50 & 127 & 129 \\
\hline 24 & 2 & 75 & 145.7 & -21.5 & 146.2 & -26.7 & 8.32 & 3.46 & 2.41 & 196 & 143 \\
\hline \multicolumn{12}{|c|}{ Site 153} \\
\hline 19 & 1 & 118 & 243.7 & 19.3 & 255.0 & 5.3 & 8.81 & 3.45 & 2.55 & 40 & 71 \\
\hline 20 & 1 & 147 & 64.1 & 13.4 & 47.4 & 0.8 & 5.88 & 3.28 & 1.79 & 51 & 81 \\
\hline 20 & 2 & 82 & 5.5 & 40.7 & 22.5 & 3.6 & 3.52 & 3.02 & 1.16 & 40 & 65 \\
\hline
\end{tabular}

At Site 152 the limestone samples below the diabase were taken very close to the baked contact. However, the directions of magnetization were similar to those of the unaltered limestone above the diabase, but quite different from the diabase itself which was reversely magnetized.

\section{CONCLUSIONS}

The central Caribbean results agree with those from the surrounding area which includes the northern part of Colombia and Venezuela, but not with paleomagnetic results from further south in the continent. This is consistent with the view that a Caribbean plate has moved since the Cretaceous in a different manner than the adjacent North American and South American plates. The magnetic pole positions based on Caribbean data (Table 3) suggest that the Caribbean tectonic plate has undergone considerable rotation relative to the adjacent plates. The magnetization inclinations from the present study suggest that the Caribbean plate was also in lower latitudes during the past than it is at present.

\section{REFERENCES}

Creer, K. M., 1962. Palaeomagnetism of the Serra Geral Formation. Geophys. J. Roy. Astron. Soc. 7 (1), 1.

- 1970. A Paleomagnetic Survey of South American Rock Formations. Phil. Trans. Roy. Soc. London. 267 (1183), 457.

Guja, N. H. and Vincenz, S. A., 1971. Equatorial Paleopoles of Some Cretaceous Rocks on Jamaica and Polarity Transition Periods (abs.). EOS, Trans. Am. Geophys. Union. 52 (4), 188.

Fahrig, W. F., Irving, E. and Jackson, G. D. 1971. Paleomagnetism of the Franklin Diabases. Can. J. Earth Sci. $8(4), 455$.

Larochelle, A., 1968. Paleomagnetism of the Monteregian Hills: New Results. J. Geophys. Res. 73 (10), 3239.

MacDonald, W. D. and Opdyke, N. D., 1972. Tectonic Rotations Suggested by Paleomagnetic Results from Northern Colombia, South America J. Geophys. Res. 77, 5720 .

Watkins, N. D. and Cambray, F. W. 1970. Palaeomagnetism of Cretaceous Dikes from Jamaica. Geophys. J. Roy. Astron. Soc. 212, 163. 
TABLE 2

Comparison of Site Inclinations with Axial Dipole Field Inclinations and Present Inclinations

\begin{tabular}{|c|c|c|c|c|c|c|}
\hline \multirow[b]{2}{*}{ Site } & \multirow[b]{2}{*}{ Latitude } & \multirow[b]{2}{*}{ Longitude } & \multirow{2}{*}{$\begin{array}{c}\text { Axial } \\
\text { Geocentric } \\
\text { Inclination }\end{array}$} & \multirow{2}{*}{$\begin{array}{l}\text { Present }^{\mathrm{a}} \\
\text { Inclination } \\
\text { at Site }\end{array}$} & \multicolumn{2}{|c|}{ Site Inclination } \\
\hline & & & & & NRM & 100 oe \\
\hline 146 & $15.13^{\circ} \mathrm{N}$ & $69.38^{\circ} \mathrm{W}$ & 28.4 & 46 & +42.9 & +16.9 \\
\hline 150 & $14.51^{\circ} \mathrm{N}$ & $69.36^{\circ} \mathrm{W}$ & 27.4 & 46 & +20.6 & -7.8 \\
\hline 151 & $15.02^{\circ} \mathrm{N}$ & $73.41^{\circ} \mathrm{W}$ & 28.2 & 46.5 & $+26.4^{b}$ & $+9.7 b$ \\
\hline 152 & $15.88^{\circ} \mathrm{N}$ & $74.61^{\circ} \mathrm{W}$ & 29.7 & 47 & mixed & -3.2 \\
\hline 153 & $13.97^{\circ} \mathrm{N}$ & $72.44^{\circ} \mathrm{W}$ & 26.5 & 45.5 & +24.5 & +3.2 \\
\hline
\end{tabular}

${ }^{\mathrm{a}}$ From charts.

b Average of only two specimens.

TABLE 3

Summary of Cretaceous Paleomagnetic Data for the Caribbean Area, for North America and for South America

\begin{tabular}{|c|c|c|c|c|}
\hline $\begin{array}{l}\text { Country of } \\
\text { Origin of } \\
\text { Data }\end{array}$ & $\begin{array}{r}\text { Cret: } \\
P \\
\text { Loc }\end{array}$ & $\begin{array}{l}\text { leous } \\
\text { lion }\end{array}$ & $\begin{array}{l}\text { Cretaceous } \\
\text { Field } \\
\text { Inclination } \\
\text { at Sampling } \\
\text { Stations }\end{array}$ & Reference \\
\hline N. America & $68 \mathrm{~S}$ & $8 \mathrm{E}$ & $18-23$ & Larochelle, 1968 \\
\hline Brazil & $78 \mathrm{~S}$ & $54 \mathrm{E}$ & $37-40$ & Creer, 1962 \\
\hline $\begin{array}{l}\text { Peru } \\
\text { Argentina }\end{array}$ & $63 \mathrm{~S}$ & $30 \mathrm{E}$ & $32-37$ & Creer, 1970 \\
\hline Colombia & $80 \mathrm{~S}$ & $72 \mathrm{~W}$ & $8-12$ & Creer, 1970 \\
\hline Venezuela (1) & $68 \mathrm{~N}$ & $53 \mathrm{E}$ & $2-5$ & Creer, 1970 \\
\hline (2) & $81 \mathrm{~S}$ & $120 \mathrm{~W}$ & $15-18$ & Creer, 1970 \\
\hline \multirow[t]{4}{*}{ Jamaica } & $70 \mathrm{~S}$ & $12 \mathrm{~W}$ & $15-19$ & $\begin{array}{l}\text { Watkins and } \\
\text { Cambray, } 1970\end{array}$ \\
\hline & $12 \mathrm{~S}$ & $9 \mathrm{E}$ & $0-2$ & $\begin{array}{l}\text { Watkins and } \\
\text { Cambray, } 1970\end{array}$ \\
\hline & $12 \mathrm{~S}$ & $4 \mathrm{E}$ & $7-11$ & $\begin{array}{l}\text { Guja and Vincenz, } \\
1971\end{array}$ \\
\hline & 1S & $21 \mathrm{E}$ & $13-17$ & $\begin{array}{l}\text { Guja and Vincenz, } \\
1971\end{array}$ \\
\hline Colombia & $10 \mathrm{~N}$ & $20 \mathrm{E}$ & $0-2$ & $\begin{array}{l}\text { MacDonald and } \\
\text { Opdyke (in } \\
\text { preparation) }\end{array}$ \\
\hline
\end{tabular}


W. LOWRIE, N. D. OPDYKE

TABLE 4

Summary for Results of Limestone Specimens

\begin{tabular}{|c|c|c|c|c|c|c|c|c|c|c|c|}
\hline \multirow{3}{*}{ نั } & \multirow{3}{*}{ : } & \multirow{3}{*}{ 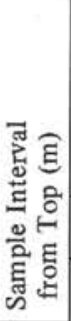 } & \multicolumn{4}{|c|}{ Direction } & \multirow{3}{*}{ 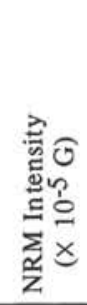 } & \multirow{3}{*}{ 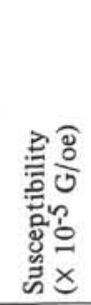 } & \multirow[b]{3}{*}{ - } & \multirow{3}{*}{ 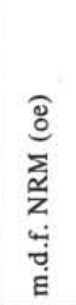 } & \multirow{3}{*}{ 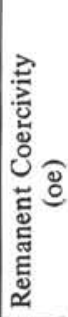 } \\
\hline & & & \multicolumn{2}{|c|}{ NRM } & \multicolumn{2}{|c|}{100 oe } & & & & & \\
\hline & & & $\mathrm{D}$ & I & $\mathrm{D}$ & I & & & & & \\
\hline \multicolumn{12}{|c|}{ Site 146 Above Diabase } \\
\hline 41 & 1 & 20 & 40.0 & 4.2 & 42.8 & 3.9 & 7.57 & 6.82 & 1.11 & 187 & 310 \\
\hline 41 & 1 & 24 & 39.2 & 8.2 & 47.7 & 7.2 & 6.55 & 5.28 & 1.24 & 152 & 312 \\
\hline 41 & 1 & 29 & 191.9 & 14.6 & 201.7 & 26.7 & 4.79 & 3.46 & 1.38 & 187 & 291 \\
\hline \multicolumn{12}{|c|}{ Site 146 Below Diabase } \\
\hline 41 & 2 & 128 & 281.4 & 15.0 & 285.5 & 6.3 & 5.64 & 9.37 & 0.60 & 189 & 224 \\
\hline 41 & 2 & 132 & 275.7 & 8.6 & 286.1 & 5.0 & 4.92 & 6.42 & 0.77 & 169 & 226 \\
\hline 41 & 2 & 136 & 281.7 & 7.7 & 287.2 & 11.6 & 4.69 & 5.81 & 0.81 & 191 & 238 \\
\hline 41 & 2 & 141 & 282.7 & 19.7 & 288.7 & 16.5 & 6.11 & 7.70 & 0.79 & 187 & 247 \\
\hline 41 & 2 & 143 & 283.3 & 18.1 & 288.2 & 14.6 & 8.31 & 8.49 & 0.98 & 229 & 252 \\
\hline \multicolumn{12}{|c|}{ Site 152 Above Diabase } \\
\hline 23 & 1 & 119 & 36.5 & 30.7 & 34.1 & 29.0 & 4.13 & 10.4 & 0.40 & 198 & 235 \\
\hline 23 & 1 & 122 & 53.0 & 37.6 & 44.9 & 33.8 & 3.93 & 11.0 & 0.36 & 199 & 235 \\
\hline \multicolumn{12}{|c|}{ Site 152 Below Diabase } \\
\hline 23 & 1 & 144 & 114.9 & 30.4 & 105.3 & 25.0 & 0.98 & 3.48 & 0.28 & 182 & 252 \\
\hline 23 & 1 & 148 & 118.8 & 29.1 & 110.8 & 24.7 & 0.89 & 4.32 & 0.20 & 131 & 238 \\
\hline
\end{tabular}

